\title{
Threshold Concepts in Irish Early Childhood Education and Care Practice Placements
}

\author{
Mark Taylor* \\ Institute of Technology Sligo, Ireland
}

\begin{abstract}
The education theory 'Threshold Concepts' has become popular as a way to examine significant learning experiences for higher-education students across a range of academic disciplines and professional training programmes. This article presents findings from a small-scale qualitative study in north-west Ireland, which used the theory as a way to examine the nature of key learning experiences for Early Childhood Education and Care (ECEC) undergraduate students during practice placements. The paper proposes that their critical learning experience necessitates them successfully planning, implementing and reviewing an intervention with young children in preschool settings. The paper should be of interest to ECEC undergraduate students, practice placement agencies and college lecturers: the stories of the ups and downs of students' learning experiences during ECEC practice placements are depicted.
\end{abstract}

Keywords: Early Childhood Education and Care, practice placement; threshold concept, threshold practice

\section{Introduction}

The number of Irish graduates with Early Childhood Education and Care (ECEC) degrees has increased rapidly in recent years (Mhic Mhathúna and Taylor, 2012: i). An important constituent of their undergraduate degree programmes is the learning experiences they undergo during practice placements. The nature of these learning experiences remains generally under-researched despite their importance for professional formation. As an educator, I was interested in understanding the learning challenges and opportunities undergraduate ECEC students encounter during practice placements. I conducted a small-scale qualitative study with ECEC students and practice placement supervisors to understand ECEC students' learning journeys during practice placements, and this article presents and discusses the findings from the study. I hoped that by employing a narrative approach, these student learning journeys might be portrayed in a more authentic and realistic way. Specifically, this article considers the nature of key learning experiences during Irish ECEC practice placements for ECEC degree programme students in north-west Ireland. Employing the education theory 'Threshold Concepts' (Meyer and Land 2003), the substantive aim was to explore the nature of the threshold learning experiences for these students during placements, including their troublesome, integrative and transformative dimensions. To realise these substantive and theoretical aims, the practice placement stories of ECEC final-year undergraduate students and their practice placement supervisors were analysed.

Aligning these substantive, theoretical and methodological aims, this paper considers the following research questions which were examined in the study:

- What do stories of ECEC undergraduate students and practice supervisors reveal about the nature of the threshold learning experience during practice placements?

- What do stories of ECEC students and practice supervisors tell about troublesome aspects of threshold concepts?

- What do stories of ECEC students and practice supervisors tell about integrative aspects of threshold concepts? 
- What do stories of ECEC students and practice supervisors tell about transformative aspects of threshold learning experiences?

The paper is structured as follows. The education theory 'Threshold Concepts' is briefly outlined and critiqued. The methodological approach employed in the study is then summarised and justified. Thereafter, findings in relation to the four research questions are presented and briefly discussed.

\section{Threshold Concepts}

The education theory 'Threshold Concepts' emerged relatively recently (Entwistle 2005: 4-5), yet has been applied extensively to explain critical learning experiences of higher-education students (Cousin 2006: 5). The theory claims 'there are certain concepts, or certain learning experiences, which resemble passing through a portal, from which a new perspective opens up, allowing things formerly not perceived to come into view' (Land, Meyer, and Baillie 2010: ix). Going through the portal enables students to understand essential elements of a discipline or a profession. 'Threshold Concepts' have a number of key features: transformative; integrative; irreversible; troublesome and bounded (Land, Meyer, and Baillie 2010: ix-x; Cousin 2006: 4; Meyer and Land 2003: 6), and these features constitute the 'Threshold Concepts' framework which researchers have applied in their investigations.

Burchmore, Irvine, and Carmichael (2007: 20-21) claimed that researchers have used the 'Threshold Concepts' framework in a number of ways, one of which has included efforts to detect the content of threshold concepts within particular disciplines or professions. Little research to date, however, has been undertaken in this area in ECEC. But one way of understanding how the 'Threshold Concepts' framework can be applied to ECEC students' learning experiences during practice placements is to review how the framework has been applied in investigating the nature of key learning experiences within comparable professional degree programmes containing college and practice placement learning elements. What is principally discernible from such a review is that researchers accentuate different aspects of the 'Threshold Concepts' framework, leading to problems of generalizability in knowledge claims. For instance, while Tanner (2011) interviewed practice supervisors to identify threshold concepts in training occupational therapists (OTs), she was particularly interested in understanding the transformative journey OT students undergo. Clouder (2005), while noting all of Meyer and Land's (2005) elements, focused more on troublesome and transformative aspects in examining difficulties encountered by occupational therapy and physiotherapy students moving from college to the student practitioner workspace. Tanner (2011) and Clouder (2005) agree that health professional students need to be touched emotionally during practice placements, but appear to disagree over the extent to which these affective experiences are significant for professional identity formation. For Clouder, the affective aspects of patient-professional interactions lead to a transformation in the student's professional identity because a change occurs in her understanding of what it means to care. In contrast, Tanner offers a multidimensional construction of what constitutes a threshold concept for OT students, stressing the significance of affective, performative and structural factors.

Tanner's and Clouder's accounts implicitly reveal the elasticity of the 'Threshold Concepts' framework, perhaps supporting a view that this education theory lacks explanatory rigour. Rowbottom (2007: 263), for instance, argued that threshold concepts have been 'defined in a way that makes it impossible, even in principle, to empirically isolate them', suggesting that Meyer and Land (2003) 'not only fail to specify what is essential to a threshold concept, but also neglect to explain what they understand a concept to be'. Demonstrating this imprecision, Irvine and Carmichael (2009: 106) assisted participants to identity threshold concepts or experiences within eight disciplinary areas, and noticed that threshold concepts were interpreted in different ways: 'eureka' moments, integrative 'big ideas', and boundaried ways of thinking and practising. Chalasani (2010: 2), more radically, stated that threshold concepts cannot be identified, but that concepts contained in people's minds have thresholds.

Despite these reservations, the 'Threshold Concepts' framework remains popular in higher-education research. Possibly this is because the framework's elements can be shaped together to create an appealing and universal narrative form: the protagonist - namely the student - overcomes obstacles 
by learning how to integrate and apply knowledge, and by doing so, transforms his or her social status (Yorke: 2013).

\section{Research Design and Methods}

The methodological approach employed in this study was narrative inquiry: as Willig (2012: 152) argued, 'it is through constructing narratives about their lives that people organise and bring meaning to their experiences'. ECEC practice placements take place over time, and ECEC supervisors and students engage in a particular social world, so a narrative approach enables us to appreciate how ECEC practice supervisors and students understand learning experiences within practice placement settings.

Six final-year ECEC undergraduate students and six ECEC agency supervisors were interviewed to obtain detailed stories of students' learning journeys during practice placements. There had been no supervisory relationship between these supervisors and the students. While students could provide 'insider' accounts, practice supervisors could offer a more seasoned perspective, informed by their own practice and supervisory experiences. However, the intention of the research was not to examine for similarities or differences in students' and supervisors' accounts. Instead, as this was a small-scale research study, the intention was to illuminate the nature of threshold learning experiences for ECEC students during practice placements from the stories of ECEC students and ECEC placement supervisors. Final-year undergraduate ECEC students were chosen for interviews, as they had undertaken two practice placements and could reflect on their learning experiences during these placements. I am a visiting placement tutor for ECEC students and established a number of links with ECEC agencies, and six supervisors from these agencies agreed to be interviewed.

The research was conducted in line with the research ethics protocol of the researcher's highereducation institution. The researcher was bound by a code of professional ethics which addresses issues such as informed consent, confidentiality, and harm to research participants. Permission was sought and received from the Head of the Department of Social Sciences to conduct this research. Ethical principles were applied in the research, following the British Educational Research Association's (2011) Ethical Guidelines for Educational Research. The background, purpose and possible benefits of the study were explained to potential respondents, who were also informed that their consent to participate in the study was voluntary. I also guaranteed to safeguard respondents' identity by using pseudonyms. I explained to potential student and supervisor respondents that the research project fulfilled the dissertation element of a MA Degree in Learning and Teaching and I gained their approval to publish the research findings to improve the training and education of ECEC practitioners. I acknowledged that while I was a lecturer and a visiting placement tutor, I was interested in hearing students' and supervisors' stories, however critical, of college and practice placement experiences. But as there was a power differential between student respondents and me, it was important to reassure students that potential criticisms of the ECEC degree programme or placement experiences, or painful or difficult personal accounts, would not result in negative consequences for them. Crucially, I was not teaching or assessing students' work at the time of their interviews nor would I do so again. ECEC practice placement agencies in Ireland agree to supervise students on a voluntary and unpaid basis; at any time they can refuse to supervise students. Consequently, I felt that ECEC supervisors genuinely volunteered to participate in the research and that the issue of coercion did not arise. It was vital to apply these ethical principles to reassure respondents and to strengthen the research findings' validity.

Topic guides were created to structure interviews with respondents, with a number of subjects chosen to address the study's research questions. Structural and content analyses of stories were undertaken. The structural model (see Esin 2011: 104) examines how narrative is created and how different elements in a structure operate. The approach treats personal narratives as a text, which functions as a representation of past events in the form of a story. The focus of analysis in the structural model is on the way an event is told in a story text. A number of features are associated with conducting a content analysis, but my main concern involved identifying themes within people's stories. The difference between a straightforward thematic analysis and a thematic analysis taking 
place within a narrative framework is that, in the latter, themes can be analysed in relation to sequences of events or experiences occurring over time. Looking for themes in this way within a narrative framework seemed appropriate given that students were likely to undergo an experiential and learning journey across time in their placements. Transcripts were analysed to identity stories of practice placement experiences, using Labov and Waletzky's structural framework (in Esin 2011: 104). Employing the 'Threshold Concepts' framework, I identified narrative themes (Esin 2011: 108) related to troublesome, integrative and transformative elements of practice placements, as I felt these themes could help to reveal both the learning journeys and critical learning experiences which students undergo. Irreversible and bounded elements were not investigated; it was deemed unlikely that students at the start of their professional ECEC careers would have sufficient insight or experiences to evaluate an irreversible learning experience or demarcate professional role boundaries.

\section{Findings}

My findings are at best provisional because of limited data. Nevertheless, they provide a comparative basis for future research.

\section{What do stories of ECEC undergraduate students and practice supervisors reveal about the nature of the threshold learning experience during practice placements?}

The study's principal finding is that the threshold learning experience involves ECEC students successfully planning, implementing and reviewing an intervention with young children in a preschool setting. But to get to the stage of successfully undertaking an intervention, students must overcome troublesome placement experiences and integrate personal, academic and agency knowledge. Successfully completing an intervention such as an activity with younger children reveals to students the possibility that they can perform as ECEC practitioners; a successful intervention also increases the likelihood of them directing agency tasks during the remaining part of their practice placement. In other words, they become transformed: from being always directed in what they do to playing a more active and self-directed role in the placement agency. These various elements were witnessed in final-year ECEC undergraduate Una's story.

Initially, Una struggled early on during placement: she was afraid of directing activities with younger children. However, after spending a number of weeks in the placement agency and becoming familiar with procedures, activities and routines, Una recollected that one day her placement supervisor said: 'You come in tomorrow with your own activity, you do it yourself with the children'. The next day she was nervous going into placement, but by integrating knowledge gained from college with an understanding of the placement environment and various stakeholders' needs, Una successfully devised and implemented a children's activity: 'I read a story with the kids - I kind of made it up myself. We did table top activities and different things and I supervised them'. Una judged how well the activity went by assessing the children's response:

[...] the children kept their concentration a good while, and then they were able to reflect on what they were doing; it showed they were kind of paying attention to what I was asking them to do and they sat there for a good 10 or 15 minutes, so I thought that was kind of an achievement. (Una, final-year ECEC student)

The successful execution of this activity laid the foundations for Una to take on a more creative and resourceful placement role, by directing other activities with the children:

And then I was doing activities and things on my own all the time. And in the 10th and 11th week I was doing so many things on my own. I definitely think you need to do that - it was very scary. (Una, final-year ECEC student) 
Una's confidence grew as a result of successfully completing these activities, a transformation recognised by her visiting college tutor: 'the supervisor from the college said that I was a totally different person in 12 or 13 weeks'.

While Una's story revealed a threshold learning experience involving a group of children, other finalyear students told stories about threshold experiences involving one-to-one encounters. For example, Haven, a final-year student, discussed her 'eureka' moment during a one-to-one encounter with a young girl:

When I was working in the hospital, a girl couldn't leave her room, she was there all day and I got to go in the evening to make a Valentine's day card for her, her face just lit up, it made me melt inside, I know that this made such a difference to this girl's day, so that would be my eureka moment. (Haven, final-year ECEC student)

In addition, Avril, another student, revealed how she adapted an activity for a group of younger children to respond to the needs of a particular child:

The more I came in early the more I realised that he was starved of attention, he was the middle-child, like he wasn't getting the attention he craved and that's why he acted like this; I could do an activity with the children and he would come over and break everything and it wasn't because he wanted to break it, it was because he wanted to sit by me, the things that I learnt spoke volumes, reality just hit - this was the issue all along; he didn't want to act like this, he wanted alone time, you wouldn't value the importance of what you were doing unless you came to a certain level academically. (Avril, final-year ECEC student)

Both of these experiences affected Haven and Avril. Rather than seeing children as some abstract 'other', the students saw the children as having unique needs. But at the same time, just as Una had to organise an activity with a group of children, Haven and Avril had to plan, execute and review their interventions for individual children.

Supervisor Marlene outlines the journey ECEC students undergo during practice placements, moving from a place where they are told what to do, to a time when they become familiar with rules and routines, to a situation where they perform activities and evaluate their performance:

At the same time then this [...] to have as well the opportunity that you can do it your own way, it's kind of 'I just have to do what I'm told, this instruction' [...] when they're confident enough 'okay I know the children now, I know the rules so that's what I can do within my little frame here' and they do it themselves and that gives them a good bit of 'oh okay now finally I'm on the stage here, I'm performing, this is what I have to do' - that's another level, they're on, and after that I find they're much more confid - 'ok that's done, phew, off the shoulders, and apart from that, l've learnt a bit', you know, I find that's a good step for them, that's a great thing. (Marlene, ECEC supervisor)

\section{What do stories of ECEC students and practice supervisors tell about troublesome aspects of threshold concepts?}

For those students with little or no previous childcare work experiences, the first few weeks of practice placements can be challenging. Judy, a student respondent, reflecting back on her first practice placement noted:

The first few couple of weeks were overwhelming, didn't know what to do or anything because it was the first time that I was in a crèche and I hadn't a clue about whether I liked it or not [...] (Judy, final-year ECEC student)

In the early stages of placement, ECEC students share a particular property with wobblers in their care: both are trying to find their feet. Students have left college and entered an unfamiliar learning and social environment. They have to get to know ways of seeing and doing things in their placement 
agency (e.g. how children are welcomed to the setting; daily and weekly programmes; how rules and regulations impact on day-to-day work; etc.). Acquiring this knowledge does not come quickly or overnight, so the early phase of placement can be particularly troubling for students, inducing difficult emotions and tiredness, as final-year ECEC student Una reflected:

When I first went out on placement I used to find it so hard, I used to dread going in in the mornings, I used to hate it when they asked me to do things, I would be afraid that I would get it wrong or something, if I tried to take on or organise an activity myself [...] the first couple of weeks, I used to come home from work and fall on the couch, it was so tiring, and you stand on your feet all day and you don't get to sit down much. (Una, final-year ECEC student)

Marlene, a community preschool supervisor, describes the challenge ECEC students must overcome to become ready to undertake a threshold learning experience. Part of a student's journey involves identifying how the placement organisation functions as 'it's all new territory', particularly so for those students who have had little or no prior work experience in preschool settings:

[...] okay what are the rules here, what am I dealing with? what's going on here?' and that's a lot, and certainly for somebody who has no professional work experience [...] they have nothing to compare it with, there is no language [...] they have no language they can talk [...] (Marlene, supervisor)

At the same time, the agency milieu can hamper students' progress. For example, Heidi, a supervisor, highlighted the busyness and noisiness of the placement environment, conditions unfamiliar to many ECEC students, conditions with which they have to come to terms:

Well you have to see that a preschool setting is a very dynamic environment [...] it's very busy and [...] I mean busy as in many people think their workplace is busy but preschool you walk into the door and you're full-on until you leave again, so that's 8 hour full-on hard work [...] (Heidi, supervisor)

At the same time there was a recognition that ECEC students differ in the level of their personal resilience, influencing how quickly they learn to settle in the practice placement environment. For example, Heidi indicated that students respond to placement knockbacks in different ways:

[...] some other students might pick up on something that didn't work out and not exactly go the opposite way, but might take longer to re-fuel [...] so it depends very much on how they face challenges and how they work or figure out for themselves how something doesn't work out, how do I deal with this [...] that's sort of a way. (Heidi, supervisor)

But even when a level of personal resilience is evident, it can still remain a challenge for some students to literally find their voice to initiate engagements with younger children. Liz, for example, provided an example of thinking processes involved in seeking her supervisor's permission to institute an activity:

Yeah, It was nerve-racking to know where your limits, how you can say 'can I do this?' or you know it's getting the confidence to say 'can I take this activity today, or can I' - and then you're always thinking in the back of your mind you need to be supervised in everything you do and you need to make sure that you're not stepping the mark saying 'can I do this, but you need to stand and watch me', and you're not getting annoy-, well they need to be in the room with you obviously. (Liz, final-year ECEC student)

The early stages of practice placements can be difficult for ECEC students as they try to understand the everyday practices of ECEC agencies and their personnel. Before undertaking activities with young children, students need to understand organisational culture (including routines) and integrate this understanding with other types of knowledge. 


\section{What do stories of ECEC students and practice supervisors tell about integrative aspects of threshold concepts?}

To successfully execute activities with younger children, ECEC students integrate their developing understanding of agency culture with knowledge acquired outside the placement environment. Students draw on experiences from their personal and college lives to plan, execute and review interactions and activities with younger children.

\section{College Knowledge}

Supervisors and students recognised the benefits of bringing learning from college to practice placements. One supervisor noted that college supplied the 'theory' underpinning ECEC practice: students learnt 'the reasoning behind certain things'. Supervisors identified the importance of particular modules taught at college (e.g. child development). While students can make productive use of their own life experiences to plan activities for younger children, knowledge acquired at college can reduce the risk of students making use of incompatible life experiences, as supervisor Maria highlighted:

[...] because we are providing care on a larger level, what can go wrong there, how to handle food [...] it would probably be okay if you cook for your family but when you're dealing with children, if someone made a case that they're coming with food poisoning, how do you prove it's not us that did it [...] (Maria, supervisor)

\section{Non-college Knowledge}

Students also make use of their pre-college life experiences on practice placements, such as babysitting and looking after younger siblings. Babysitting experiences for ECEC student Judy created a form of tacit knowledge to use on placement. When asked about factors informing her approach to interacting with younger children, she replied:

It was something I always done, whenever I was babysitting, I was always playing with them at their level; it was something I always did, never really thought about it. (Judy, final-year ECEC student)

Students also drew on technical knowledge learnt outside college. For example, Judy's story also highlighted how a craft learnt in the Girl Guides' movement informed a placement activity. Specifically, Judy adapted a craft used with older children for younger children in her ECEC placement setting:

Because I had done it with the brownies - it was a craft I had done with the brownies - the brownies are a bit older than the kids in the crèche so I had to simplify it down for them, for the kids in the crèche. (Judy, final-year ECEC student)

One step removed from students' day-to-day concerns of adapting to an ECEC agency culture or passing college learning requirements, perhaps supervisors such as Maria are best placed to recognise an intrinsic disposition frequently overlooked in students' stories: a capacity to care underpins ECEC practice:

And I think that - definitely the care is there - to widen the spectrum, that can be taught, but there has to be an initial thing - has to be there in my case - it's not - if somebody doesn't care, that has to be a general thing, it's not just about children. (Maria, supervisor)

\section{Agency Knowledge}

Students have to understand a practice agency's policies and procedures. Generally this knowledge gets introduced during an induction phase. Students may be asked to read documents and may be given the opportunity to discuss policies and procedures with various staff members. Students also 
obtain a form of 'know-how' gained from practical experience. Marlene, a supervisor, described this type of knowledge as 'streetwise' knowledge, a kind of colloquial knowledge learnt gradually in the practice environment:

[...] and the other stuff, being streetwise, to detect potential [in children] [...] I can tell because I've observed those two [students] for two weeks and that stuff you learn as you are going along, you just get a feeling for stuff, that's something that has to be developed over a period. (Marlene, supervisor)

Maria, another supervisor, used the word 'streetwise' to convey this idea of everyday knowledge learnt by the student on placement:

But also there's kind of like risk assessment and also it's kind of like being streetwise at a work level to make sure the children are going to be safe and also to create an atmosphere that's tolerable as well and if you're kind of going off one way, you're going to try to bring it back a little bit [...] (Maria, supervisor)

\section{What do stories of ECEC students and practice supervisors tell about transformative aspects of threshold learning experiences?}

Successful completions of key learning experiences depend upon students becoming familiar and comfortable with an agency's routines and ways of working. Successful completions lead to intrinsic and extrinsic transformations in how students embody and perform the role of a student-practitioner. While the transitional phase of finding one's voice can be laborious for students, the consequence of doing so becomes manifested in how students present themselves. For example, Marlene, a supervisor, noted the transitional phase of settling into an agency and familiarising themselves with work tasks can be tiring for students. But getting through this phase can be rewarding, with confidence becoming embodied: 'from that very tired face they become a bit more bubbly and a bit more relaxed and the coolness starts up and that's great'.

Across the 13-week placement period, Maria, a supervisor in a community preschool setting, also witnessed students maturing both personally and professionally: "but most of them, toward [...] during the weeks they mature, I feel definitely that they mature in their own character and personality as well as in a professional way'.

Maria also suggested students can became more expressive as they became more confident executing tasks. To illustrate the nature of this transformation, she told a story of how ECEC students become more communicative and assertive concerning the agency task of transporting preschool children between an agency and home. Initially, at the beginning of placement, ECEC students can be 'really shy and have to be told to do something'. After a few weeks, students 'might think it but they wouldn't come out and say well maybe we should head off now... at the beginning, a lot of them wait to be told'. Later on, students start to say, "oh, it's half-two, will I go on [e.g. preschool bus], whatever?" So gaining confidence on placement from successfully completing a child-orientated activity can lead to students initiating further activities as Maria remarked:

[...] they just take it upon themselves to organise activities or go and sort out dinners or whatever, not afraid to go and do it and be well you know told off - 'why did you decide? [...]' they just use their own initiative. (Maria, supervisor)

\section{Discussion}

One runs the risk of flirting with essentialism in trying to identify a threshold concept in ECEC. The risk materialises since the education theory 'Threshold Concepts' holds a certain psychological appeal, bringing to life the Indiana Jones within us: if only we look hard enough, we can find the Holy Grail of key learning portals within disciplines and professions. However, the nature of the social world within 
which ECEC is located means that it is a high risk strategy to make knowledge claims with high degrees of certainty and generalisation (Wallace and Wray, 2011: 86) concerning what constitutes a threshold concept, not least because of variations within social structural and personal factors (e.g. type of ECEC agency; quality of placement supervision; college learning requirements; capacity of students to reflect, etc.) which affect student learning. At the same time, if Bruner's (2009) contention is correct in that narrative knowledge is a credible way to order experience, then it can be plausibly argued that stories offer an alternative mode to understand the social world of respondents.

In this study, ECEC supervisors and students tell us how they make sense of the practice placement experience, and these stories reveal the journeys students undertake over the course of a 13-week placement. The early days of a practice placement frequently challenge the ECEC student, so it must be difficult for her to envisage successfully executing, later on in placement, a threshold learning experience. In these early days, the ECEC student can struggle to find her feet and voice; she watches the organisation at work and observes day-to-day routines: she is soaking up the workplace culture. In the first few weeks of placement, supervisors frequently tell ECEC students what to do protecting students from themselves and children in their care. Meanwhile students have to gauge and respond to supervisors' expectations. But at some stage the ECEC student steps from the shadows and moves to a position where she plans, executes and reviews an activity or interaction with young children: she is no longer fully dependant on a supervisor telling her exactly what to do. For the essence of becoming a professional is to learn how to competently direct encounters with service users (Eraut, 2008: 6). The successful management of encounters and activities with younger children may therefore constitute a threshold learning experience for ECEC students during a practice placement, as the capability to manage encounters signifies the developing capacity of students to perform as ECEC practitioners. Threshold learning experiences are not limited to one type of interaction with children. For example, students told stories about encounters taking the form of oneto-one interactions or group-focused activities with children. What matters is that the student plans, executes and reviews these activities.

The student undertakes these activities by integrating knowledge from different sources such as college, her own life and the placement agency. Trevithick (2008: 1212) suggested social professionals such as social workers draw on three types of knowledge to inform their knowledge base: theoretical knowledge, factual knowledge and practical knowledge. In this study, ECEC students drew on knowledge from both inside and outside their placement agency. Unsurprisingly, ECEC students apply their understanding of theories taught at college to placement situations. Avril, as previously highlighted, employed child development theory to resolve a situation involving a disruptive boy seeking attention; this represents a form of theoretical knowledge for Trevithick (2008: 1213). Perhaps more surprisingly, students also put to use knowledge from their own lives knowledge not acquired at college- to design activities for younger children; Judy, for example, remembered and adapted a Girl Guides' activity. For Trevithick (2008: 1230), Judy's activity represented a type of practice knowledge (i.e. what she did), but even more than that, it signified the outcome of a process where she created knowledge to be applied. While I remain uncertain about every cognitive process employed to adapt learning from previous experiences (e.g. Judy's Girl Guides' activity), at very least what can be interpreted from Judy's account is that she used memory, creativity and problem-solving processes: active learning skills. Utilising these features to devise an activity may signify to Stepney (2000: 21) that the student has embarked on the path to developing practice wisdom, a distinctive professional knowledge created from transferring personal and professional experiences to developing practice-based activities. Yet it would still be fascinating to further explore how this cumulative understanding materialises, not least because different knowledge domains are likely to value truth statements about the social world in different ways. Interestingly, the tasks undertaken (i.e. planning, executing and reviewing) to complete a threshold learning experience echo tasks comprising competent professional practice. For Eraut (2008: 6) competence in professional practice is assessed by how well a practitioner performs actions of assessment, choice, implementation and meta-cognition (e.g. monitoring situation).

Morgan (2012: 218) argued that the essential quality defining a threshold concept is its transformative aspect, and this can be witnessed by a student's changing deportment and by her willingness to embrace a role directing agency tasks. So while the ECEC student remains at best a novice 
practitioner - on the periphery - she can take inspiration from her placement achievements, as she moves forward on her ECEC degree programme. As Hall (2002: 192) suggested, achieving goals such as executing threshold activities - results in an inner sense of success, raising self-confidence and providing evidence to support a view that one's professional identity is forming. Students also reset their ontological understanding (Land, Meyer and Baillie 2010: ix-x) of what it means to perform as an ECEC practitioner. The ontological shift relates to their journey to become a self-directed and reflective practitioner. Or put another way, as a result of successfully planning, executing and reviewing an intervention with younger children, students transform their perspective (Mezirow 1991: $167)$ on their capability to engage younger children.

Executing a threshold learning experience in ECEC also involved a caring dimension, a facet of the threshold concept identified in the training of health care practitioners; Clouder (2005) and Tanner (2011), for example, claimed physiotherapy and OT shared a common threshold experience with care at the crux. I cannot profess, however, that the affective capacity to care for others constituted a core part of ECEC threshold concept. The capacity to care is instead a vital aptitude which needs to be present in those wanting to become ECEC practitioners. As Tamm (2010: 69) suggested, a person's personal identity, consisting of values and principles, directs her attention towards particular professions and supports the development of her professional identity. The capacity to care, in other words, is an indispensable quality which ECEC practitioners need to have, but it does not in itself constitute a threshold concept.

\section{Conclusion}

Over the course of practice placements, students move from a position on the periphery of an agency to a place where they assume a self-directed quasi-practitioner role. Central to this transformation is the successful execution of an intervention such as an activity with younger children, which consists of planning, implementation and review stages. Yet to get to the point of undertaking such an intervention, students must want to care for younger children, overcome troublesome placement experiences and integrate knowledge from college, their own lives and the practice agency. This proposition of course assumes that placement agencies and supervisors have the wherewithal to offer adequate learning opportunities. The successful execution of an intervention leads to embodied and behavioural transformations in the students' lives. They feel and look more confident. They can initiative more interactions with children. They start to believe that they have the capacity to work as ECEC practitioners. While Land, Meyer, and Baillie (2010: ix-x) specified elements constituting a threshold concept, what has become clear from this study is the narrative interconnectedness of these features for ECEC students during practice placements.

Threshold Concepts provide us with a framework to examine the learning journey ECEC students undergo during practice placements. Colleges can prepare ECEC students for this journey by highlighting possible stages they will experience such as dislocation, observation, mimicking, supervisor-directed and self-directed encounters with younger children. Students need to be reassured that ECEC students generally find the early part of placement tiring and emotionally challenging, but that over time, with the support of supervisors and through their own perseverance, they will settle, becoming familiar with routines and will successfully interact with younger children.

Students need to be reassured that they can use learning from their lives to inform the content of activities and interactions with younger children in ECEC agency settings. Some of this learning can be formal - for example, ECEC students can adapt arts and crafts learnt at school or in community groups. Other learning is more tacit, where students, for example, make use of babysitting experiences. ECEC college lecturers need to be aware that students draw on these lived experiences. Students at college could benefit from exploring the advantages and disadvantages of adapting non-formal learning for placement activities. 


\section{References}

British Education Research Association. (2011) Ethical Guidelines for Educational Research. [online] available from <www.bera.ac.uk/system/files/3/BERA-Ethical-Guidelines-2011.pdf> [accessed 15 December 2013]

Bruner, J. S. (2009) Actual Minds, Possible Worlds. Cambridge, MA, USA: Harvard University Press

Burchmore, H., Irvine, N. and Carmichael, P. (2007) Threshold Concepts: A Review of Related Literature. available from<www.esrc.ac.uk/my-esrc/grants/RES-139-250361/outputs/Read/d92bc3fd-58fb-4af2-a343-af965381db46> [accessed 15 September 2011]

Chalasani, P. (2010) Health \& IIIness; Sanity and Insanity; Biological and Psychological...: Are They Real or Abstracts? available from<www.mhhe.heacademy.ac.uk/silo/files/padmajachalasani.pdf $>$ [accessed 24 June 2014]

Clouder, L. (2005) 'Caring as a 'Threshold Concept': Transforming Students in Higher Education into Health(care) Professionals'. Teaching in Higher Education 10 (4), 505-517

Cousin, G. (2006) 'An introduction to Threshold Concepts. Planet 17, 4-5

Entwistle, N. J. (2005) 'Learning Outcomes and Ways of Thinking across Contrasting Disciplines and Settings in Higher Education'. Curriculum Journal 16 (1), 67-82

Eraut, M. (2008) How Professionals Learn through Work. available from<www.surreyprofessionaltraining.pbworks.com/f/How+Professionals+Learn+through+Wo rk.pdf $>$ [accessed 24 June 2014]

Esin, C. (2011) 'Narrative Analysis Approaches'. In Qualitative Research Methods in Psychology: Combining Core Approaches. ed. by Frost, N. Maidenhead: Open University Press

Hall, D. (2002) Careers In and Out of Organizations. London: Sage

Irvine, N. and Carmichael, P. (2009) 'Threshold Concepts: A Point of Focus for Practitioner Research'. Active Learning in Higher Education 10 (2), 103-119

Land, R., Meyer, J. and Baillie, C. (2010) 'Editors' Preface: Threshold Concepts and Transformational Learning'. In Threshold Concepts and Transformational Learning. ed. by Meyer, J. Land, R. and Baillie, R.. Rotterdam, Netherlands: Sense Publishers

Meyer, J. and Land, R. (2003) Threshold Concepts and Troublesome Knowledge: Linkages to Ways of Thinking and Practicing within the Disciplines. [online] available from $<$ www.etl.tla.ed.ac.uk//docs/ETLreport4.pdf $>$ [accessed 24 June 2014]

Meyer, J. and Land, R. (2005) 'Threshold Concepts and Troublesome Knowledge (2): Epistemological Considerations and a Conceptual Framework for Teaching and Learning'. Higher Education 49 (3), 373-388

Mezirow, J. (1991) Transformative Dimensions of Adult Learning. San Francisco, CA: Jossey-Bass

Mhic Mhathúna, M. and Taylor, M. (eds.) (2012) Early Childhood Education and Care. An Introduction for Students in Ireland. Dublin, Ireland: Gill and Macmillan

Morgan, H. (2012) 'The Social Model of Disability as a Threshold Concept: Troublesome Knowledge and Liminal Spaces in Social Work Education'. Social Work Education 31 (2), 215-226

Rowbottom, D. (2007) 'Demystifying Threshold Concepts'. Journal of Philosophy of Education 41 (2), 263-270 
Stepney, P. (2000) 'The Theory to Practice Debate Revisited'. In Social Work Models, Methods and Theories. ed. by Stepney, P. and Ford, D. Lyme Regis: Russell House

Tamm, T. (2010) Professional Identity and Self-concept of Estonian Social Workers.a vailable from<http://tampub.uta.fi/bitstream/handle/10024/66631/978-951-44-81154.pdf? sequence $=1 \geq$ [accessed 24 June 2014]

Tanner, B. (2011) 'Threshold Concepts in Practice Education: Perceptions of Practice Educators'. British Journal of Occupational Therapy 74 (9), 427-434

Trevithick, P. (2008) 'Revisiting the Knowledge Base of Social Work: A Framework for Practice'. British Journal of Social Work 38 (6), 1212-1237

Wallace, M. and Wray, A. (2011) Critical Reading and Writing for Postgraduates. London: Sage

Willig, C. (2012) Qualitative Interpretation and Analysis in Psychology. Maidenhead: Open University Press

Yorke, J. (2013) Into The Woods: How Stories Work and Why We Tell Them. London: Penguin UK 